\title{
Elucidation of conformational characteristics and configurational properties of poly ((R)-3-hydroxybutyrate) by ab initio statistical mechanics
}

\author{
Yuji Sasanuma and Shiori Katsumata
}

Conformational free energies and geometrical parameters derived from ab initio molecular orbital (MO) calculations for monomeric and dimeric model compounds of poly ( $R$ )-3-hydroxybutyrate) (PHB) were introduced into the refined rotational isomeric state (RIS) scheme to yield the characteristic ratio, configurational entropy, configurational internal energy, bond conformations and averaged geometrical parameters of PHB. The reliability of the MO calculations was confirmed through comparison with ${ }^{1} \mathrm{H}$ and ${ }^{13} \mathrm{C}$ nuclear magnetic resonance experiments for the monomeric model compound. The characteristic ratio (5.60) derived from the refined RIS calculations for the unperturbed PHB chain at $25^{\circ} \mathrm{C}$ is in satisfactory agreement with the experimental values (6.1-6.3). The crystalline PHB chain is known to adopt the $\mathrm{ttg}^{+} \mathrm{g}^{+}$conformation in the repeating unit. A previous study revealed that a trimeric $(R)$-3-hydroxybutyrate substrate bound on a PHB depolymerase lies in the $\operatorname{ttg}^{+} \mathrm{g}^{+}$and $\mathrm{tg}^{-} \mathrm{tt}$ conformations. In our MO calculations, the former conformation is the most stable, and the latter is metastable but further stabilized by intermolecular $\mathbf{C}=\mathbf{O} \cdots \mathbf{H}-\mathrm{N}$ and $\mathbf{C}=\mathbf{O} \cdots \mathbf{H}-\mathbf{0}$ hydrogen bonds on the enzyme.

Polymer Journal (2013) 45, 727-737; doi:10.1038/pj.2012.203; published online 21 November 2012

Keywords: conformation; molecular orbital calculation; NMR; poly((R)-3-hydroxybutyrate); RIS scheme

\section{INTRODUCTION}

$\operatorname{Poly}\left((R)\right.$-3-hydroxybutyrate) (PHB, Figure $1 \mathrm{a}^{\prime}$ ), is a reserve substance of energy and carbon for microorganisms and will be degraded both intracellularly and extracellularly. The biodegradable polyester comprises only primitive atomic groups such as methine, methylene, methyl and ester groups but possesses an equilibrium melting point $\left(T_{\mathrm{m}}^{0} \approx 203^{\circ} \mathrm{C}\right)^{1}$ much higher than those of symmetric aliphatic polyesters, such as poly(ethylene adipate) $\left(T_{\mathrm{m}}^{0} \approx 65^{\circ} \mathrm{C}\right)$ and poly(ethylene suberate) $\left(75^{\circ} \mathrm{C}\right),{ }^{2}$ thus being expected to be utilized as an environment-friendly renewable thermoplastic. ${ }^{3}$ It is obvious that the unique properties and functions of PHB come from its conformational characteristics owing to the primary structure. In a previous study, configurational properties of PHB were simulated by the traditional rotational isomeric state (RIS) scheme $^{4,5}$ with $3 \times 3$ statistical weight matrices including up to adjacent-bond correlations, but the computations yielded unperturbed chain dimensions much smaller than the experimental observations. ${ }^{6}$

In the present study, we have treated $\mathrm{PHB}$ as an ordinary polymer without paying any particular attention to its microbiological aspects to investigate the polymeric chain in terms of polymer physicochemistry. By ab initio statistical mechanics calculations and nuclear magnetic resonance (NMR) experiments, we have attempted to reveal its intrinsic conformational characteristics. In recent years we have tacked conformational analyses of aromatic polyesters, ${ }^{7,8}$ and the methodology there could be expected to be developed for PHB. Here, we have employed the refined RIS algorithm ${ }^{9}$ that $(1)$ adopts $27 \times 27$ statistical weight matrices including up to four-bond correlations (between atomic groups separated by six bonds), (2) eliminates nonexistent conformations from the ensemble and (3) employs $a b$ initio molecular orbital (MO) calculations to derive reliable conformational free energies and geometrical parameters.

So far, solution NMR experiments have been carried out for PHB and related compounds to estimate their bond conformations. ${ }^{10-15}$ These studies have paid attention exclusively to the $\mathrm{CH}\left(\mathrm{CH}_{3}\right)-\mathrm{CH}_{2}$ bond (bond $\mathrm{c}$ in Figure $\left.1 \mathrm{a}^{\prime}\right)$. On the other hand, we have prepared a ${ }^{13} \mathrm{C}$ labeled model compound (monomer- ${ }^{13} \mathrm{C}$, Figure $1 b^{\prime}$ ) and measured its ${ }^{1} \mathrm{H}$ and ${ }^{13} \mathrm{C}$ NMR with various solvents at different temperatures to enable NMR conformational analysis about the $\mathrm{O}-\mathrm{CH}\left(\mathrm{CH}_{3}\right)$ as well as $\mathrm{CH}\left(\mathrm{CH}_{3}\right)-\mathrm{CH}_{2}$ bonds. Although experimental observations on structures and properties of PHB have been accumulated, the results are not always consistent 


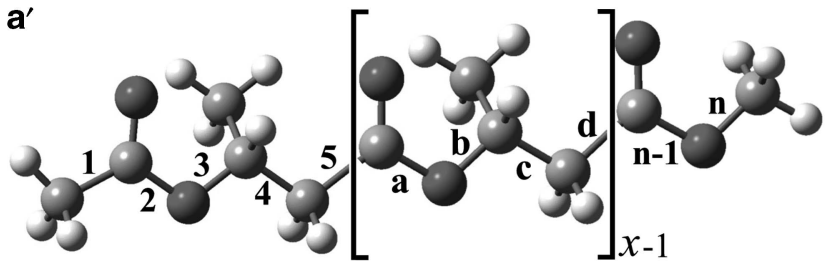

$\mathbf{b}^{\prime}$
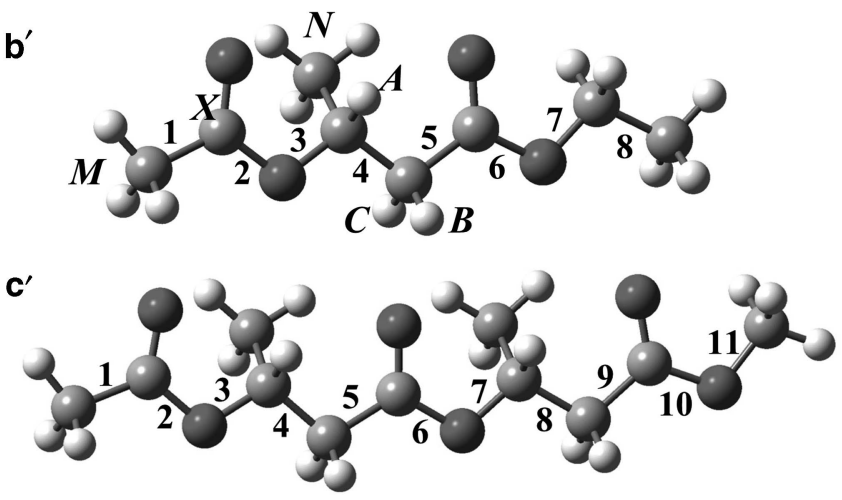

Figure 1 All-trans conformations of $\left(a^{\prime}\right)$ poly $((R)$-3-hydroxybutyrate (abbreviated as $\mathrm{PHB}),\left(\mathbf{b}^{\prime}\right)(R)$-ethyl 3-acetoxybutanoate (termed 'monomer' here), and ( $\left.\mathbf{c}^{\prime}\right) \quad(R)-(R)-4$-methoxy-4-oxobutan-2-yl 3-acetoxybutanoate ('dimer'). The skeletal bonds are labeled as indicated. The atoms of monomer are partly designated as $\mathrm{A}, \mathrm{B}, \mathrm{C}, \mathrm{M}, \mathrm{N}\left({ }^{1} \mathrm{H}\right)$ and $\mathrm{X}\left({ }^{13} \mathrm{C}\right)$ to represent the spin system $\left(\mathrm{ABCM}_{3} \mathrm{~N}_{3} \mathrm{X}\right)$ of ${ }^{1} \mathrm{H}$ and ${ }^{13} \mathrm{C}$ nuclear magnetic resonance (NMR) spectra (Figure 2). A full color version of this figure is available at Polymer Journal online.

with each other. We have examined them and chosen the reliable data for comparison with our RIS calculations.

Herein we report our conformational analysis of PHB and its model compounds, discuss its solution properties, crystal structure and interactions with a PHB depolymerase in terms of the conformational characteristics, and suggest the origins of its unique properties and functions.

\section{METHODS}

Synthesis of ethyl 3-acetoxybutyrate- ${ }^{13} C$ (monomer- $\left.-{ }^{13} C\right)$

The reaction here, accompanied by generation of hydrogen chloride, was carried out in a draft chamber. Acetyl chloride-1- ${ }^{13} \mathrm{C}(1.0 \mathrm{~g}, 12.6 \mathrm{mmol}, 99$ atom $\%{ }^{13} \mathrm{C}$, Sigma-Aldrich Japan, Tokyo, Japan) was added with a Pasteur pipette to ethyl DL-3-hydroxybutyrate $(1.41 \mathrm{~g}, 11 \mathrm{mmol}$, Tokyo Chemical Industry, Tokyo, Japan) stirred in a flask connected to a calcium-chloride drying tube, with the flask bathed in ice water. After being stirred at ambient temperature for a day, the reaction mixture was gradually heated up to $120^{\circ} \mathrm{C}$ (to remove residual hydrogen chloride), cooled down to room temperature, dropped into distilled water in a vial container and left to stand for a day to separate into two layers. Only the lower layer was sucked up with a Pasteur pipette and identified by ${ }^{1} \mathrm{H}$ NMR as ethyl 3-acetoxybutanoate- ${ }^{13} \mathrm{C}$ (Figure $\left.1 \mathrm{~b}^{\prime}\right)$. The yield was $0.522 \mathrm{~g}(27 \%)$.

\section{NMR measurements}

${ }^{1} \mathrm{H}\left({ }^{13} \mathrm{C}\right)$ NMR spectra were recorded at $500 \mathrm{MHz}(126 \mathrm{MHz})$ on a JNMECA500 spectrometer (JEOL, Tokyo, Japan) equipped with a variable temperature controller in the Chemical Analysis Center of Chiba University. The measurement temperatures were $15,25,35,45$ and $55^{\circ} \mathrm{C}$ and maintained within $\pm 0.1{ }^{\circ} \mathrm{C}$ fluctuations. Free induction decays were accumulated 64 (256) times and zero filled so that the digital resolution would be smaller than $0.01 \mathrm{~Hz}$ point ${ }^{-1}$. The $\pi / 2$ pulse width, data acquisition time and recycle delay were $5.7(3.3) \mu \mathrm{s}, 7.0(2.1) \mathrm{s}$ and $2.0(2.0) \mathrm{s}$, respectively. In the ${ }^{13} \mathrm{C} \mathrm{NMR}$ experiments, the gated decoupling technique was employed under the conditions given in the above parentheses. The solvents were cyclohexane$d_{12}$, benzene- $d_{6}$, chloroform- $d$, methanol- $d_{4}$ and dimethyl- $d_{6}$ sulfoxide, and the solute concentration was about $5 \mathrm{vol} \%$. The NMR spectra were simulated with the gNMR program ${ }^{16}$ to yield the chemical shifts and coupling constants.

\section{MO calculations}

Density functional and $a b$ initio MO calculations were carried out with the Gaussian03 program ${ }^{17}$ installed on an HPC5000-Z800 computer (HPC Systems, Tokyo, Japan). For each conformer of monomer and dimer (Figures $1 b^{\prime}$ and $1 c^{\prime}$ ), the geometrical parameters were fully optimized at the B3LYP/6-311 $+\mathrm{G}(2 \mathrm{~d}, \mathrm{p})$ level, and the thermal-correction term to the Gibbs free energy (at $25^{\circ} \mathrm{C}$ ) was also calculated. With the optimized geometry and the same basis set, the MP2 energy was computed. All self-consistent field calculations were conducted under the tight convergence. The Gibbs free energy at $25{ }^{\circ} \mathrm{C}$ was evaluated from the MP2 and thermal-correction energies, being given here as the difference from that of the all-trans conformer and denoted as $\Delta G_{k}$ ( $k$ : conformer). The $\Delta G_{k}$ values including solvation effects were also calculated for monomer in ethylene dichloride (EDC) and dimer in EDC or trifluoroethanol (TFE) with the integral equation formalism of the polarizable continuum model. ${ }^{18}$

NMR spin-spin coupling constants of monomer were calculated at the B3LYP/6-311 + + G(3df,3pd)//B3LYP/6-311+ + G(3df,3pd) level. ${ }^{19}$ Bond lengths, bond angles and dihedral angles of $(R)$-isopropyl 3-(propionyloxy)butyrate were optimized at the B3LYP/6-31G(d) level to be used in the refined RIS computations ${ }^{9}$ on PHB (Supplementary Table S2, Supplementary Information).

It should be noted that the dihedral angle is defined here according to the tradition in polymer science: ${ }^{4}$ trans $(\mathrm{t}) \sim \pm 0^{\circ}$, cis $(\mathrm{c}) \sim \pm 180^{\circ}$, gauche ${ }^{+}$ $\left(\mathrm{g}^{+}\right) \sim \pm 120^{\circ}$ and gauche $e^{-}\left(\mathrm{g}^{-}\right) \sim-120^{\circ}$.

\section{RESULTS AND DISCUSSION}

${ }^{1} \mathrm{H}$ and ${ }^{13} \mathrm{C}$ NMR of monomer- ${ }^{13} \mathrm{C}$

Figure 2 shows examples of ${ }^{1} \mathrm{H}$ and ${ }^{13} \mathrm{C}$ NMR spectra of monomer${ }^{13} \mathrm{C}$ (Figure $1 \mathrm{~b}^{\prime}$ ). The spectra, observed from the identical sample at the same temperature, should be reproduced by a set of ${ }^{1} \mathrm{H}-{ }^{1} \mathrm{H}$ and ${ }^{13} \mathrm{C}-{ }^{1} \mathrm{H}$ coupling constants; on this assumption, the spectra were reproduced as shown in Figure 2, and the coupling constants were determined as ${ }^{3} J_{\mathrm{AB}}=7.50,{ }^{3} \mathrm{~J}_{\mathrm{AC}}=5.70,{ }^{3} J_{\mathrm{XA}}=3.17,{ }^{2} \mathrm{~J}_{\mathrm{XM}}=-6.83$ and ${ }^{3} J_{\mathrm{AN}}=6.34 \mathrm{~Hz}$. For the spin symbols, see Figure $1 \mathrm{~b}^{\prime}$. The ${ }^{3} J_{\mathrm{AB}},{ }^{3} J_{\mathrm{AC}}$ and ${ }^{3} J_{\mathrm{XA}}$ values for all the solutions are listed in Table 1.

As illustrated in Figure $3 \mathrm{~b}^{\prime}$, the vicinal ${ }^{13} \mathrm{C}-{ }^{1} \mathrm{H}$ coupling constant $\left({ }^{3} J_{\mathrm{XA}}\right)$ can be expressed as a function of trans $\left(p_{\mathrm{t}}\right)$ and gauche ${ }^{+}\left(p_{\mathrm{g}+}\right)$, and gauche $^{-}\left(p_{\mathrm{g}-}\right)$ fractions of bond 3 :

$$
{ }^{3} J_{\mathrm{XA}}=J_{\mathrm{G}} p_{\mathrm{t}}+J_{\mathrm{T}}^{\prime} p_{\mathrm{g}+}+J_{\mathrm{G}}^{\prime} p_{\mathrm{g}-}
$$

where $J_{\mathrm{G}}, J_{\mathrm{T}}^{\prime}$ and $J_{\mathrm{G}}^{\prime}$ are defined in Figure $3 \mathrm{~b}^{\prime}$. The bond conformations are normalized as

$$
p_{\mathrm{t}}+p_{\mathrm{g}+}+p_{\mathrm{g}-}=1
$$

The MO calculations yielded the coefficients of equation (1) as follows: $J_{\mathrm{G}}=3.19, J_{\mathrm{T}}^{\prime}=8.45$ and $J_{\mathrm{G}}^{\prime}=2.84 \mathrm{~Hz}$. Inasmuch as the number of unknown parameters $\left(p_{\mathrm{t}}, p_{g+}\right.$ and $\left.p_{g-}\right)$ is three and that of equations is two, the three unknowns can not be uniquely determined; accordingly, the following assumption has been adopted: $J_{\mathrm{G}}=J_{\mathrm{G}}^{\prime}=(3.19+2.84) / 2=3.02 \mathrm{~Hz}$. Then, equation (1) can be rewritten as

$$
{ }^{3} J_{\mathrm{XA}}=J_{\mathrm{G}}\left(p_{\mathrm{t}}+p_{\mathrm{g}_{-}}\right)+J_{\mathrm{T}}^{\prime} p_{\mathrm{g}+}
$$

and the two parameters, $p_{\mathrm{t}}+p_{\mathrm{g}-}$ and $p_{g+}$, were determined as shown in Table 2. The data indicate that the $\mathrm{g}^{+}$conformation is essentially absent and that the bond conformations show little solvent dependence. The NMR results exactly agree with the MO calculations summarized in Table 4. 
a

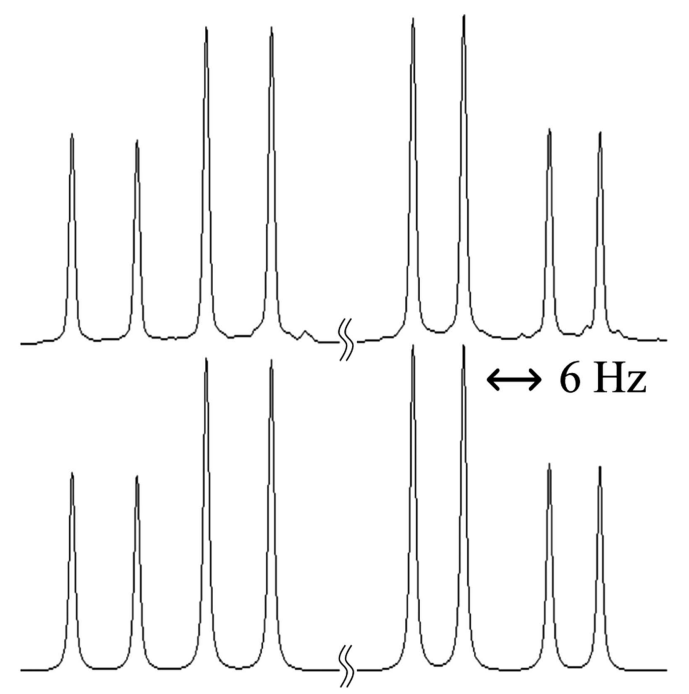

b

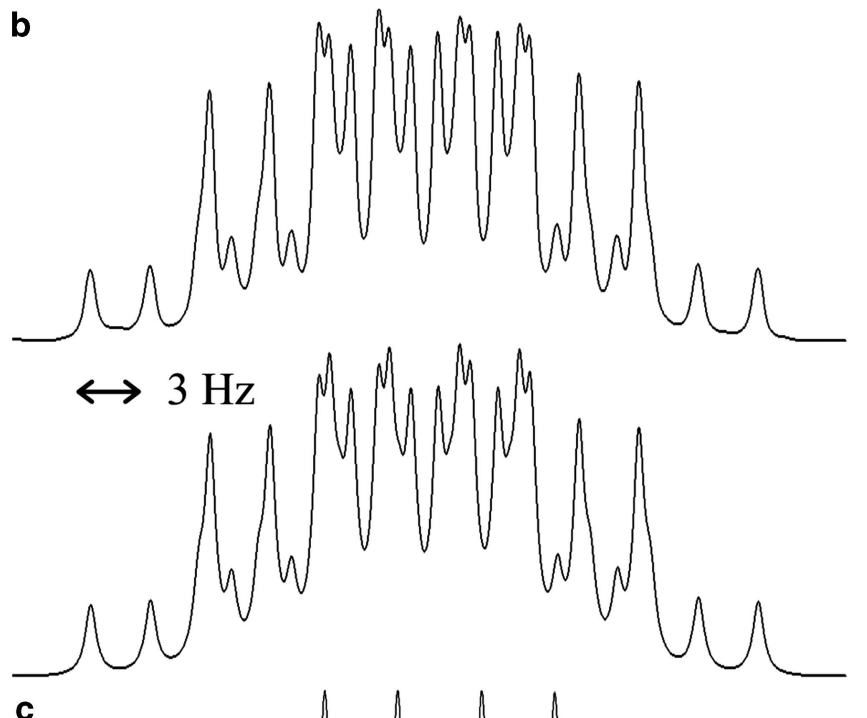

C

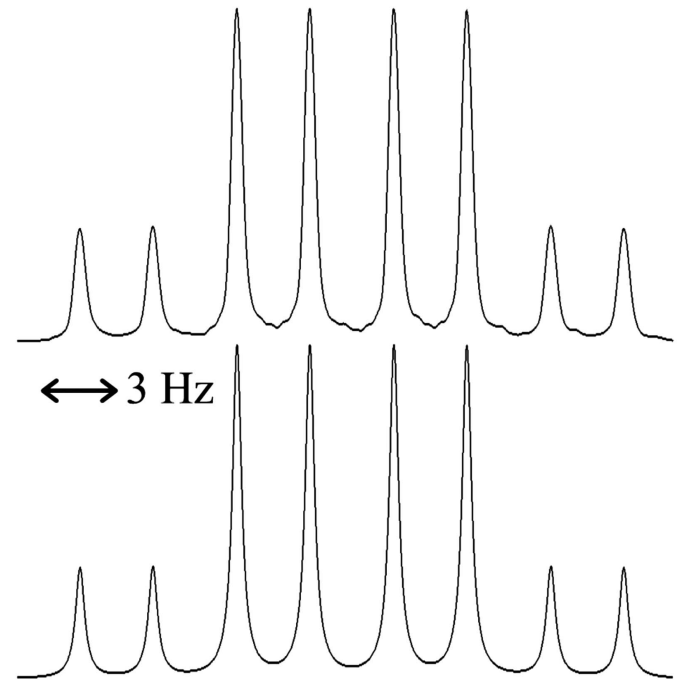

Figure $2{ }^{1} \mathrm{H}$ nuclear magnetic resonance (NMR) spectra of (a) the methylene ( $B$ and $C$, see Figure $\left.1 b^{\prime}\right)$ and (b) methine (A) protons and (c) ${ }^{13} \mathrm{C}$ NMR spectrum of the carbonyl carbon $(X)$ of monomer $-{ }^{13} \mathrm{C}$ dissolved in chloroform- $d$ at $25^{\circ} \mathrm{C}$ : above, observation; below, simulation.
Table 1 Observed vicinal ${ }^{1} \mathrm{H}-{ }^{1} \mathrm{H}$ and ${ }^{13} \mathrm{C}-{ }^{1} \mathrm{H}$ coupling constants of monomer- ${ }^{13} \mathrm{C}^{\mathrm{a}}$

\begin{tabular}{|c|c|c|c|c|c|}
\hline Solvent & Dielectric constant ${ }^{\mathrm{b}}$ & $T\left({ }^{\circ} \mathrm{C}\right)$ & ${ }^{3} \mathrm{~J}_{A B}$ & ${ }^{3} \mathrm{~J}_{A C}$ & ${ }^{3} \mathrm{~J}_{X A}$ \\
\hline \multirow[t]{5}{*}{ Cyclohexane- $d_{12}$} & 2.0 & 15 & 6.92 & 6.42 & 3.17 \\
\hline & & 25 & 6.85 & 6.43 & 3.17 \\
\hline & & 35 & 6.83 & 6.45 & 3.18 \\
\hline & & 45 & 6.78 & 6.45 & 3.18 \\
\hline & & 55 & 6.73 & 6.46 & 3.18 \\
\hline \multirow[t]{5}{*}{ Benzene- $d_{6}$} & 2.3 & 15 & 7.69 & 5.50 & 3.15 \\
\hline & & 25 & 7.61 & 5.57 & 3.16 \\
\hline & & 35 & 7.50 & 5.64 & 3.16 \\
\hline & & 45 & 7.40 & 5.71 & 3.17 \\
\hline & & 55 & 7.31 & 5.76 & 3.19 \\
\hline \multirow[t]{5}{*}{ Chloroform- $d$} & 4.8 & 15 & 7.62 & 5.65 & 3.17 \\
\hline & & 25 & 7.50 & 5.70 & 3.17 \\
\hline & & 35 & 7.43 & 5.77 & 3.17 \\
\hline & & 45 & 7.34 & 5.82 & 3.19 \\
\hline & & 55 & 7.26 & 5.87 & 3.19 \\
\hline \multirow[t]{5}{*}{ Methanol- $d_{4}$} & 32.7 & 15 & 8.15 & 5.01 & 3.16 \\
\hline & & 25 & 8.06 & 5.13 & 3.17 \\
\hline & & 35 & 7.97 & 5.18 & 3.18 \\
\hline & & 45 & 7.88 & 5.27 & 3.18 \\
\hline & & 55 & 7.80 & 5.33 & 3.20 \\
\hline \multirow[t]{4}{*}{ Dimethyl- $d_{6}$ sulfoxide } & 46.7 & 25 & 8.09 & 5.11 & 3.19 \\
\hline & & 35 & 8.00 & 5.21 & 3.20 \\
\hline & & 45 & 7.89 & 5.27 & 3.21 \\
\hline & & 55 & 7.78 & 5.35 & 3.21 \\
\hline
\end{tabular}

Two vicinal ${ }^{1} \mathrm{H}-{ }^{1} \mathrm{H}$ coupling constants between the methine (A) and methylene (B and C) protons (see Figure $\left.3 \mathrm{c}^{\prime}\right),{ }^{3} \mathrm{~J}_{\mathrm{AB}}$ and ${ }^{3} \mathrm{~J}_{\mathrm{AC}}$, are related to $p_{\mathrm{t}}, p_{g+}$ and $p_{g-}$ of bond 4 :

$$
{ }^{3} J_{\mathrm{AB}}=J_{\mathrm{G}} p_{\mathrm{t}}+J_{\mathrm{T}}^{\prime} p_{\mathrm{g}+}+J_{\mathrm{G}}^{\prime \prime} p_{\mathrm{g}-}
$$

and

$$
{ }^{3} J_{\mathrm{AC}}=J_{\mathrm{T}} p_{\mathrm{t}}+J_{\mathrm{G}}^{\prime} p_{\mathrm{g}+}+J_{\mathrm{G}}^{\prime \prime \prime} p_{\mathrm{g}-}
$$

where $J_{\mathrm{T}}$ 's and $J_{\mathrm{G}}$ 's are defined in Figure $3 \mathrm{c}^{\prime}$. The coefficients in equations (4) and (5), $J_{\mathrm{T}}$ 's and $J_{\mathrm{G}}$ 's, were chosen from experimental $J$ values of 1,3-dioxane (set A) ${ }^{20}$ or calculations with the generalized Karplus equation (set B). ${ }^{15}$ For the individual $J$ values, see the footnote of Table 2. The bond conformations were determined to be in the order of $p_{\mathrm{g}+}>p_{\mathrm{t}}>p_{\mathrm{g}-}$ and the difference between $p_{\mathrm{g}+}$ and $p_{\mathrm{t}}$ increases with solvent polarity.

By ${ }^{1} \mathrm{H}$ NMR experiments, Doi et al. ${ }^{10,11}$ and Kamiya et al. ${ }^{12}$ estimated bond conformations around bond $\mathrm{c}$ of $\mathrm{PHB}$ and poly(3hydroxybutyrate-co-3-hydroxyvalerate) as $p_{\mathrm{t}} \approx 0.4, p_{\mathrm{g}+} \approx 0.6$, and $p_{\mathrm{g}-} \approx 0.0$. Li et al. ${ }^{13,14}$ conducted ${ }^{1} \mathrm{H}$ NMR measurements for oligomers of (R)-3-hydroxybutyrate to determine the bond conformations for each repeating unit; for the second unit from the methoxy terminal, the conformational fractions were obtained as $p_{\mathrm{t}} \approx 0.2, p_{\mathrm{g}+} \approx 0.7$ and $p_{\mathrm{g}-} \approx 0.1$. These fractions are in close agreement with our RIS calculations on PHB (Table 4). By twodimensional NMR experiments, Waser et al. ${ }^{15}$ evaluated the bond conformations of 16 mer and 20mer oligo $((R)$-3-hydroxybutyrate)s to 
$\mathbf{a}^{\prime}$<smiles>CC1C(=O)CC2(C)CCC1CC2</smiles>

trans

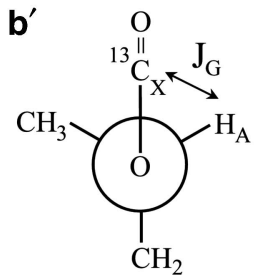

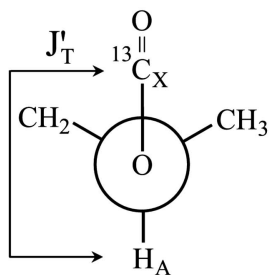

$\begin{array}{ll}\mathbf{c}^{\prime} & \mathrm{J}_{\mathrm{T}}\end{array}$

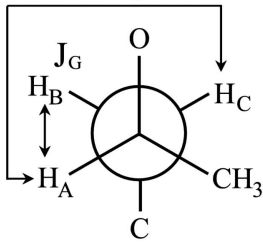

$\mathbf{d}^{\prime}$<smiles>CC12CC3CC(CC(C3)C1O)C2</smiles>

trans

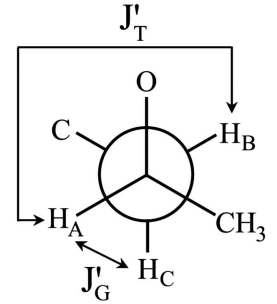<smiles>CC1C(O)C2CCC1(C)CC2</smiles>

gauche $^{+}$

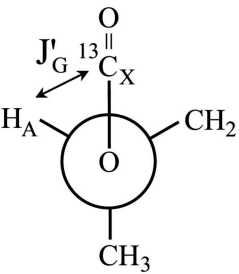

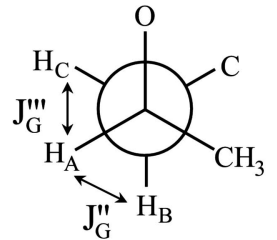<smiles>CC12CC3CC([13CH3])C1C(O)C(C3)C2</smiles>

gauche

Figure 3 Rotational isomeric states around bonds $\left(\mathbf{a}^{\prime}\right) 2,6$ and a $\left(\mathbf{b}^{\prime}\right)$ 3, 7 and $\mathrm{b}\left(\mathrm{c}^{\prime}\right)$ 4, 8 and $\mathrm{c}\left(\mathrm{d}^{\prime}\right)$ 5, 9 and $\mathrm{d}$ of monomer, dimer and poly((R)-3hydroxybutyrate) (PHB) with definitions of vicinal trans $\left(J_{T}\right)$ and gauche $\left(J_{G}\right)$ coupling constants.

be $p_{\mathrm{t}} \approx 0.35, p_{\mathrm{g}+} \approx 0.55$ and $p_{\mathrm{g}-} \approx 0.10$. These values are in satisfactory agreement with our NMR (Table 2) and MO data (Table 4). The previous NMR studies partly aimed to determine the solution structure of $\mathrm{PHB}$, in the expectation that, even in solutions, PHB would adopt a helical structure such as $2_{1}$ (two repeating units per turn) or $3_{1}$. The conformation of bond $\mathrm{c}$ was expected to provide a clue as to which helix would be formed. This problem will be discussed later.

\section{MO calculations and conformational energies}

According to the RIS approximation, the repeating unit of PHB may have $54\left(=2 \times 3^{3}\right)$ conformations; bond a has two states (trans and cis), and bonds $\mathrm{b}-\mathrm{d}$ have three $\left(\mathrm{t}, \mathrm{g}^{+}\right.$, and $\left.\mathrm{g}^{-}\right)$. The 54 conformers of monomer, generated by internal rotations around bonds $2-5$, were geometrically optimized by the B3LYP method. Of them, 34 conformers reached the individual potential minima and directly underwent the MP2 calculations to yield their Gibbs free energies, and the residual 20 were considered to be nonexistent. To investigate chain-length dependence of $\Delta G_{k}$, the 54 conformations around bonds 6-9 of dimer were also subjected to the B3LYP optimization; consequently, 33 conformers reached the stationary points, and their $\Delta G_{k}$ values are also listed in Table 3. The solvent effects were included in the MP2 calculations: EDC for monomer and dimer; TFE for dimer. Both chain-length and solvent effects are clearly seen in

Table 2 Bond conformations of monomer

\begin{tabular}{|c|c|c|c|c|c|c|c|c|c|}
\hline \multirow[b]{3}{*}{ Medium } & \multirow[b]{3}{*}{$T\left({ }^{\circ} \mathrm{C}\right)$} & \multicolumn{2}{|c|}{ Bond 3} & \multicolumn{6}{|c|}{ Bond 4} \\
\hline & & \multicolumn{2}{|c|}{ Set $a^{a}$} & \multicolumn{3}{|c|}{ Set $A^{\mathrm{b}}$} & \multicolumn{3}{|c|}{ Set $B^{C}$} \\
\hline & & $p_{\mathrm{t}+} p_{\mathrm{tg}-}$ & $p_{\mathrm{g}}$ & $p_{\mathrm{t}}$ & $p_{g}+$ & $p_{g}-$ & $p_{\mathrm{t}}$ & $p_{\mathrm{g}+}$ & $p_{g_{-}}$ \\
\hline \multirow[t]{5}{*}{ Cyclohexane } & 15 & 0.97 & 0.03 & 0.36 & 0.46 & 0.18 & 0.44 & 0.44 & 0.12 \\
\hline & 25 & 0.97 & 0.03 & 0.36 & 0.45 & 0.19 & 0.44 & 0.43 & 0.13 \\
\hline & 35 & 0.97 & 0.03 & 0.36 & 0.45 & 0.19 & 0.44 & 0.43 & 0.13 \\
\hline & 45 & 0.97 & 0.03 & 0.36 & 0.45 & 0.19 & 0.44 & 0.43 & 0.13 \\
\hline & 55 & 0.97 & 0.03 & 0.36 & 0.44 & 0.20 & 0.44 & 0.42 & 0.14 \\
\hline \multirow[t]{5}{*}{ Benzene } & 15 & 0.98 & 0.02 & 0.27 & 0.54 & 0.19 & 0.35 & 0.53 & 0.12 \\
\hline & 25 & 0.97 & 0.03 & 0.28 & 0.53 & 0.19 & 0.35 & 0.53 & 0.12 \\
\hline & 35 & 0.97 & 0.03 & 0.28 & 0.52 & 0.20 & 0.36 & 0.51 & 0.13 \\
\hline & 45 & 0.97 & 0.03 & 0.29 & 0.51 & 0.20 & 0.37 & 0.50 & 0.13 \\
\hline & 55 & 0.97 & 0.03 & 0.29 & 0.50 & 0.21 & 0.37 & 0.49 & 0.14 \\
\hline \multirow[t]{5}{*}{ Chloroform } & 15 & 0.97 & 0.03 & 0.29 & 0.53 & 0.18 & 0.36 & 0.53 & 0.11 \\
\hline & 25 & 0.97 & 0.03 & 0.29 & 0.52 & 0.19 & 0.37 & 0.51 & 0.12 \\
\hline & 35 & 0.97 & 0.03 & 0.30 & 0.51 & 0.19 & 0.37 & 0.51 & 0.12 \\
\hline & 45 & 0.97 & 0.03 & 0.30 & 0.50 & 0.20 & 0.38 & 0.49 & 0.13 \\
\hline & 55 & 0.97 & 0.03 & 0.30 & 0.50 & 0.20 & 0.38 & 0.49 & 0.13 \\
\hline \multirow[t]{5}{*}{ Methanol } & 15 & 0.97 & 0.03 & 0.22 & 0.59 & 0.19 & 0.30 & 0.59 & 0.11 \\
\hline & 25 & 0.97 & 0.03 & 0.23 & 0.58 & 0.19 & 0.31 & 0.58 & 0.11 \\
\hline & 35 & 0.97 & 0.03 & 0.24 & 0.57 & 0.19 & 0.31 & 0.57 & 0.12 \\
\hline & 45 & 0.97 & 0.03 & 0.24 & 0.56 & 0.20 & 0.32 & 0.56 & 0.12 \\
\hline & 55 & 0.97 & 0.03 & 0.25 & 0.55 & 0.20 & 0.33 & 0.55 & 0.12 \\
\hline \multirow[t]{4}{*}{ Dimethyl sulfoxide } & 25 & 0.97 & 0.03 & 0.23 & 0.58 & 0.19 & 0.31 & 0.58 & 0.11 \\
\hline & 35 & 0.97 & 0.03 & 0.24 & 0.57 & 0.19 & 0.32 & 0.57 & 0.11 \\
\hline & 45 & 0.96 & 0.04 & 0.25 & 0.56 & 0.19 & 0.32 & 0.56 & 0.12 \\
\hline & 55 & 0.96 & 0.04 & 0.25 & 0.55 & 0.20 & 0.33 & 0.55 & 0.12 \\
\hline
\end{tabular}

$a^{\prime} T_{T}=8.45 \mathrm{~Hz}$ and $J_{G}=J_{G}^{\prime}=(3.19+2.84) / 2=3.02 \mathrm{~Hz}$ ( $\mathrm{MO}$ calculations for monomer at the B3LYP/6-311 + +G(3df, 3pd) level, this study).

$J_{T}{ }_{T}=12.4, J_{G}=2.3, J^{\prime \prime}{ }_{G}=1.2$ and $J^{\prime \prime}{ }_{G}=4.9 \mathrm{~Hz}$ (from 1,3-dioxane, reference 20). $J_{T}=J_{T}{ }_{T}$ and $J_{G}=\left(J_{G}{ }_{G}+J^{\prime \prime} G_{G}+J^{\prime \prime \prime}{ }_{G}\right) / 3$ were assumed.

cFrom the generalized Karplus equation: $J_{T}=11.63, J_{G}=3.55, J_{G}=1.97, J^{\prime \prime}{ }_{G}=1.97$ and $J^{\prime \prime}=3.55 \mathrm{~Hz}$ (reference 15).

Table 3. For example, the $\Delta G_{k}$ value of a stable conformer, $\operatorname{tg}^{+} \mathrm{g}^{+}$ $(k=5)$, decreases in the order of monomer $\rightarrow$ dimer or gas (dielectric constant, 1.0) $\rightarrow$ EDC (10.1) $\rightarrow$ TFE (26.7).

Table 3 shows that the $\Delta G_{k}$ values of the same conformation are significantly different between monomer and dimer. For example, in the $\Delta G_{k}$ stability, the $\mathrm{ttg}^{+} \mathrm{g}^{+}$conformation ranks second $(-0.65 \mathrm{kcal}$ $\mathrm{mol}^{-1}$ in the gas phase) in monomer but first $\left(-1.14 \mathrm{kcal} \mathrm{mol}^{-1}\right)$ in dimer. The MP2 energies of $\mathrm{ttg}^{+} \mathrm{g}^{+}$in monomer and dimer are, respectively, -0.80 and $-1.27 \mathrm{kcal} \mathrm{mol}^{-1}$ (relative to that of the alltrans state); the difference is nearly equal to that in $\Delta G_{k}$. Its dihedral angles were optimized to be $0.84^{\circ},-27.70^{\circ}, 120.77^{\circ}$, and $131.77^{\circ}$ in bonds $2-5$ of monomer and $2.98^{\circ},-28.51^{\circ}, 119.26^{\circ}$, and $134.41^{\circ}$ in bonds $6-9$ of dimer. The potential well appears to be shifted and deepened with an increase in chain length. In addition, we calculated the $\Delta G_{k}$ values of the $\operatorname{ttg}^{+} \mathrm{g}^{+}, \mathrm{ttg}^{+} \mathrm{t}, \mathrm{tg}^{-} \mathrm{tt}$ conformations in the central (second) repeating unit of a trimer, $\mathrm{CH}_{3}[\mathrm{C}(=$ O) $\left.\mathrm{OCH}\left(\mathrm{CH}_{3}\right) \mathrm{CH}_{2}\right]_{3} \mathrm{C}(=\mathrm{O}) \mathrm{OCH}_{3}$, at the $\mathrm{MP} 2 / 6-311+\mathrm{G}(2 \mathrm{~d}, \mathrm{p}) / /$ B3LYP/6-311+G(2d,p) level with the outer (first and third) units lying in the all-trans state to obtain the following results: $\operatorname{tgg}^{+} \mathrm{g}^{+}$, -1.29 (gas) and -1.56 (EDC); $\operatorname{ttg}^{+} \mathrm{t},-0.49$ (gas) and -0.84 


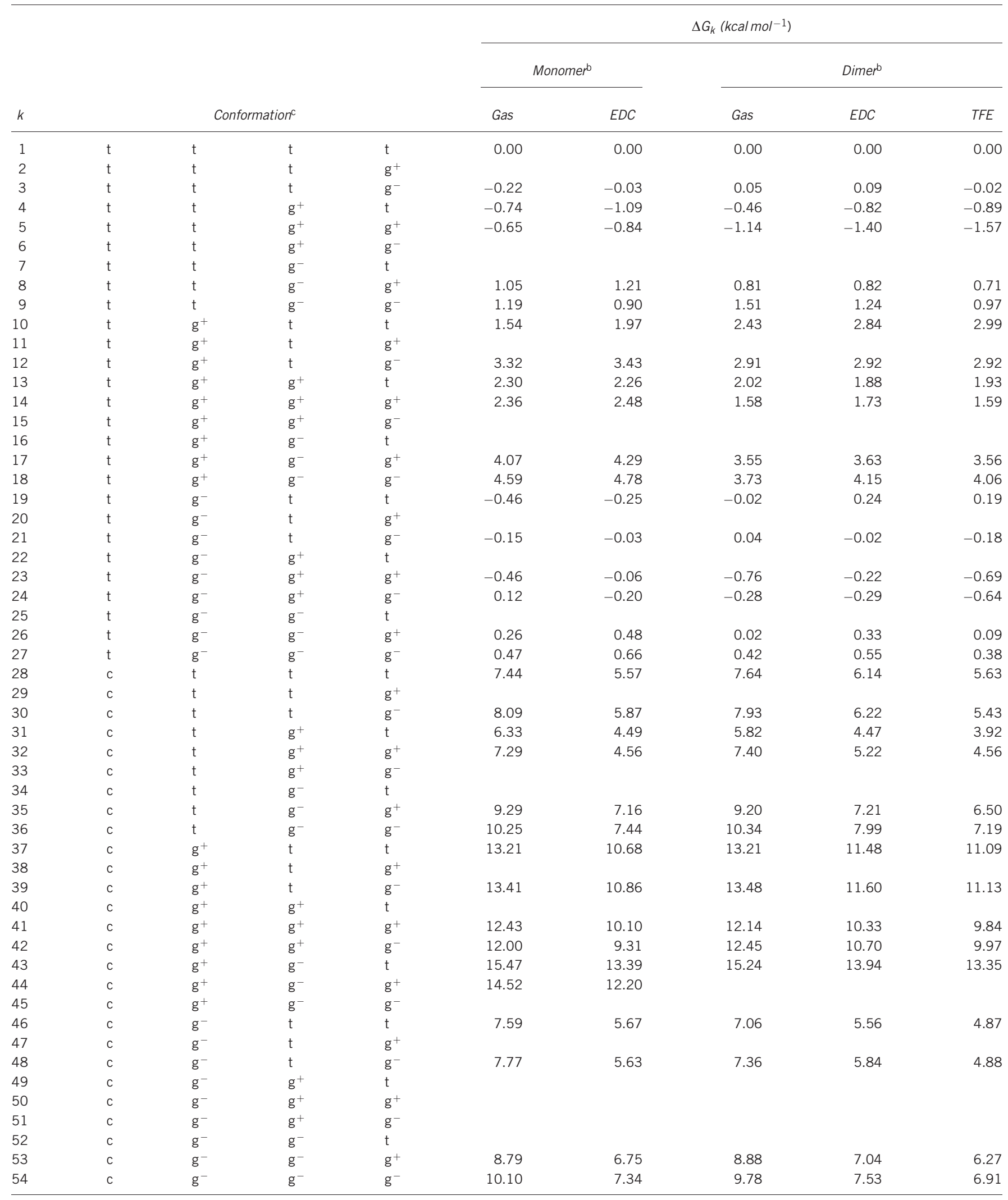

Abbreviations: EDC, ethylene dichloride; TFE, trifluoroethanol.

The blank line indicates that the geometrical optimization did not detect the potential minimum. aAt the MP2/6-311 $+\mathrm{G}(2 \mathrm{~d}, \mathrm{p}) / / \mathrm{B} 3 \mathrm{LYP} / 6-311+\mathrm{G}(2 \mathrm{~d}, \mathrm{p})$ level. Relative to the all- trans conformer. bSee Figure 1.

c Conformations of bonds 2-5 (monomer) or bonds 6-9 (dimer). 
Table 4 Bond conformations of monomer and polymer, derived from the RIS calculations with MO energies

\begin{tabular}{|c|c|c|c|c|c|c|c|c|c|c|c|c|}
\hline \multirow{2}{*}{ Medium } & \multirow{2}{*}{$T\left({ }^{\circ} \mathrm{C}\right)$} & \multicolumn{11}{|c|}{ Bond } \\
\hline & & \multicolumn{2}{|c|}{2 or a } & \multicolumn{3}{|c|}{3 or $b$} & \multicolumn{3}{|c|}{4 or $c$} & \multicolumn{3}{|c|}{5 or $d$} \\
\hline \multicolumn{13}{|l|}{ Monomer } \\
\hline \multirow[t]{3}{*}{ Gas } & 15 & 1.00 & 0.00 & 0.55 & 0.01 & 0.44 & 0.35 & 0.57 & 0.08 & 0.40 & 0.36 & 0.24 \\
\hline & 45 & 1.00 & 0.00 & 0.54 & 0.01 & 0.45 & 0.36 & 0.55 & 0.09 & 0.39 & 0.35 & 0.26 \\
\hline & 55 & 1.00 & 0.00 & 0.53 & 0.01 & 0.46 & 0.36 & 0.54 & 0.10 & 0.39 & 0.35 & 0.26 \\
\hline \multirow[t]{3}{*}{ EDC } & 15 & 1.00 & 0.00 & 0.69 & 0.01 & 0.30 & 0.24 & 0.70 & 0.06 & 0.48 & 0.31 & 0.21 \\
\hline & 25 & 1.00 & 0.00 & 0.68 & 0.01 & 0.31 & 0.25 & 0.69 & 0.06 & 0.47 & 0.31 & 0.22 \\
\hline & 35 & 1.00 & 0.00 & 0.67 & 0.01 & 0.32 & 0.26 & 0.68 & 0.06 & 0.47 & 0.31 & 0.22 \\
\hline \multicolumn{13}{|l|}{ Polymer } \\
\hline \multirow[t]{2}{*}{ Gas } & 25 & 1.00 & 0.00 & 0.75 & 0.01 & 0.24 & 0.16 & 0.69 & 0.15 & 0.19 & 0.69 & 0.12 \\
\hline & $203^{a}$ & 1.00 & 0.00 & 0.61 & 0.04 & 0.35 & 0.26 & 0.50 & 0.24 & 0.27 & 0.53 & 0.20 \\
\hline \multirow[t]{2}{*}{ EDC } & 25 & 1.00 & 0.00 & 0.86 & 0.01 & 0.13 & 0.09 & 0.83 & 0.08 & 0.19 & 0.73 & 0.08 \\
\hline & $203^{a}$ & 1.00 & 0.00 & 0.71 & 0.03 & 0.26 & 0.20 & 0.61 & 0.19 & 0.25 & 0.57 & 0.18 \\
\hline \multirow[t]{2}{*}{ TFE } & 25 & 1.00 & 0.00 & 0.86 & 0.01 & 0.13 & 0.08 & 0.83 & 0.09 & 0.16 & 0.76 & 0.08 \\
\hline & $203^{a}$ & 1.00 & 0.00 & 0.70 & 0.03 & 0.27 & 0.19 & 0.61 & 0.20 & 0.22 & 0.60 & 0.18 \\
\hline
\end{tabular}

Abbreviations: EDC, ethylene dichloride; RIS, rotational isomeric state; TFE, trifluoroethanol.

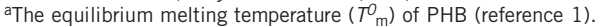

(EDC); $\operatorname{tg}^{-} \mathrm{tt},-0.03$ (gas) and 0.23 (EDC) in $\mathrm{kcal} \mathrm{mol}^{-1}$. These values are almost equal to the corresponding $\Delta G_{k}$ values of dimer (Table 3).

Table 4 shows trans/cis or trans/gauche /gauche $^{-}$ratios in bonds 2-5 of monomer. Bonds 2 and 3 hardly adopt the cis and $\mathrm{g}^{+}$ conformations, respectively. In bond 4 , the three conformations occur in the ratio of $p_{\mathrm{g}+}>p_{\mathrm{t}}>p_{\mathrm{g}-}$, and the $p_{\mathrm{g}+}$ value seems to increase with solvent polarity. These results are consistent with the above NMR observations and, interestingly, in semiquantitative agreement with those found for the $\mathrm{CH}\left(\mathrm{CH}_{3}\right)-\mathrm{CH}_{2}$ bonds of poly $((R)$ propylene oxide) $(\mathrm{PPO})^{21}$ and its model compound, $(R)-1,2-$ dimethoxypropane (DMP). ${ }^{22}$ Both NMR experiments and $\mathrm{MO}$ calculations indicate that bond 3 of monomer and bond b of PHB do not essentially adopt the $\mathrm{g}^{+}$conformation. This is probably due to the steric hindrance among the carbonyl, methylene and methyl groups as found for the $\mathrm{O}-\mathrm{CH}\left(\mathrm{CH}_{3}\right)$ bond of PPO and $\mathrm{DMP},{ }^{21}$ in which the repulsion was estimated to be about $3 \mathrm{kcal} \mathrm{mol}^{-1} .{ }^{21} \mathrm{In}$ monomer and dimer, the corresponding repulsive energy ranges from 1.5 to $3.0 \mathrm{kcal} \mathrm{mol}^{-1}$ (estimated from $\Delta G_{k}$ of $\mathrm{tg}^{+} \mathrm{tt}, k=10$ ).

Intramolecular attractive interactions of polyesters are so complicated that the sources of their conformational characteristics can not be simply assigned to well-defined close contacts between atoms (atomic groups). ${ }^{7}$ As shown in Figure 4, however, the stable conformers of monomer seem to exhibit some close contacts between the methine proton and carbonyl oxygen $(\sim 2.4$ and $2.6-2.7 \AA)$ or -O - oxygen $(2.56 \AA)$. The molecular geometry was optimized at the B3LYP/6-311+G(2d,p) level. Some of these distances are much shorter $(<2.4 \AA)$ than the sum of van der Waals radii of hydrogen $(1.2 \AA)$ and oxygen $(1.52 \AA) .{ }^{23}$ In the previous paper, ${ }^{21}$ we discussed intramolecular $(\mathrm{C}-\mathrm{H}) \cdots \mathrm{O}$ attractions $\left(\sim-1 \mathrm{kcal} \mathrm{mol}^{-1}\right)$ of PPO and DMP (see Figure $4 \mathrm{~d}$ ), and the $\mathrm{H} \cdots \mathrm{O}$ distance $(2.48 \AA$ ) was reevaluated here at the B3LYP/6-311 $+\mathrm{G}(2 \mathrm{~d}, \mathrm{p})$ level for comparison. In sum, $\mathrm{PHB}$ and $\mathrm{PPO}$ are similar in conformational preference but different in the origin.

Our MO calculations have well reproduced the NMR experiments, thus being reliable and applicable to the refined RIS calculations to evaluate configurational properties of PHB.

\section{Refined RIS calculations for PHB}

Statistical weight matrices $U_{j}$ ( $j$ : bond number) used in the refined RIS calculations for PHB have been defined in the $27 \times 27$ form to include up to fourth-order intramolecular interactions (between atomic groups separated by six bonds). For the first (second to $x$ th) repeating unit(s), Boltzmann factors $\exp \left(-\Delta G_{k} / R T\right)$ 's calculated from the $\Delta G_{k}$ values of monomer (dimer) were set in the $U_{5}\left(U_{\mathrm{d}}\right)$ matrix, because the $\Delta G_{k}$ value is a function of conformations around bonds 2-5 (6-9 or a-d). Only for the TFE solution, the dimer energies were also used in the first repeating unit. The $U_{2}-U_{4}$ and $U_{a}-$ $U_{\mathrm{c}}$ matrices are filled with unity and zero; only the existent conformations are expressed by unity. This formulation was employed for aromatic polyesters such as poly(ethylene terephthalate) $(\mathrm{PET})^{7}$ and poly(trimethylene terephthalate). ${ }^{8}$

Conformations around four bonds $3-6,4-7$ or 5-8 of dimer were also subjected to the geometrical optimization at the B3LYP/6-311+ $\mathrm{G}(2 \mathrm{~d}, \mathrm{p})$ level, and a number of conformations were found to be absent and hence removed from the ensemble (see Supplementary Table S1, Supplementary Information). The elements corresponding to the nonexistent conformations in $U_{\mathrm{a}}, U_{\mathrm{b}}$ and $U_{\mathrm{c}}$ were replaced with 

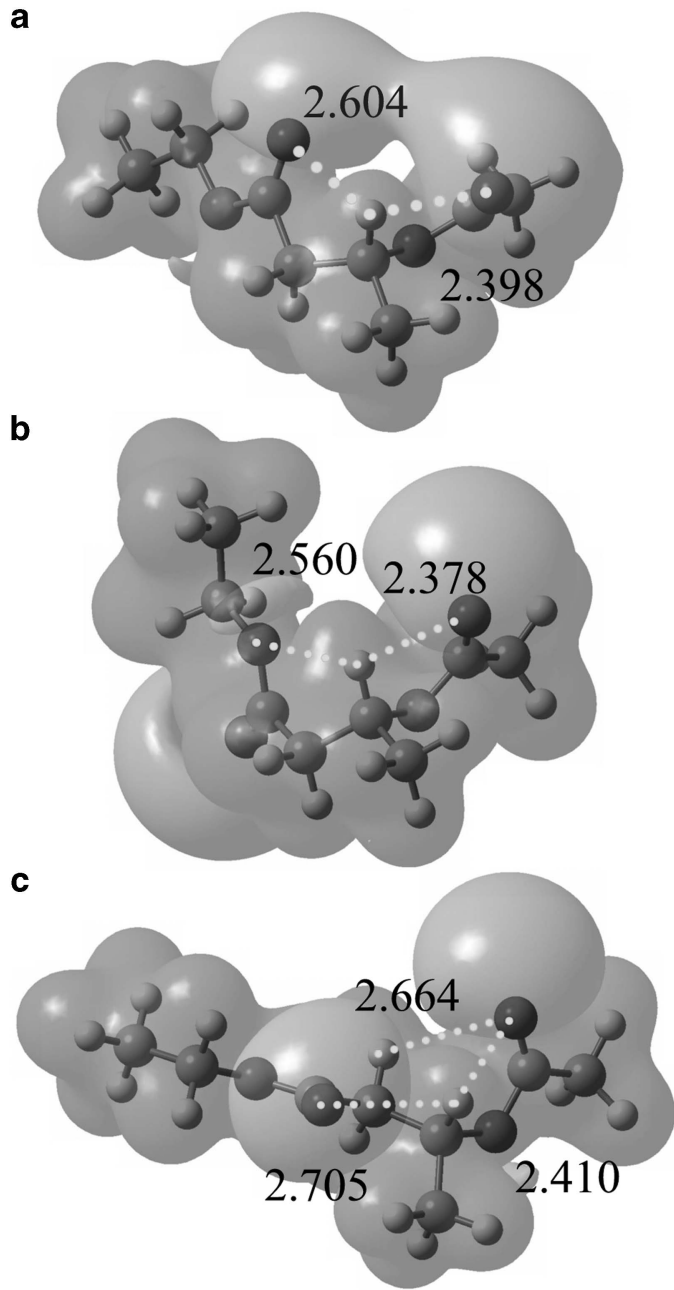

d

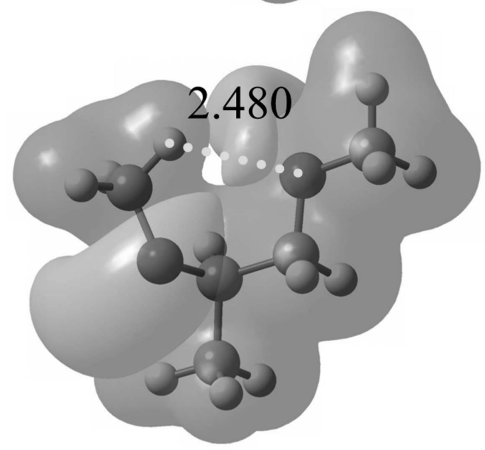

Figure 4 Stable conformers of monomer with electrostatic potential surfaces and intramolecular interactions (dotted lines): (a) $\operatorname{ttg}^{+} \mathrm{t}(k=4$ in Table 3); (b) $\mathrm{ttg}^{+} \mathrm{g}^{+} \quad(k=5) ; \quad(\mathbf{c}) \mathrm{tg}^{-} \mathrm{tt} \quad(k=19)$ in bonds $2-5$. (d) (R)-1,2Dimethoxypropane (DMP), a monomeric model compound of poly(propylene oxide) (PPO) in the $\mathrm{tg}^{+} \mathrm{g}^{-}$conformation. The numerical values represent the $\mathrm{H} \ldots \mathrm{O}$ distances in $\AA$. A full color version of this figure is available at Polymer Journal online.

zero. The refined RIS calculations were carried out with the $U_{j}$ matrices thus formulated (see Appendix, Supplementary Information) and geometrical parameters listed in Supplementary Table S2 (Supplementary Information).

Characteristic ratios, $\left\langle r^{2}>_{0} / n l^{2}\right.$ 's, calculated from the free energy sets (Table 3), are plotted against the reciprocal $\left(x^{-1}\right)$ of degree of polymerization, where $\left\langle r^{2}\right\rangle_{0}$ is the unperturbed mean-square end-

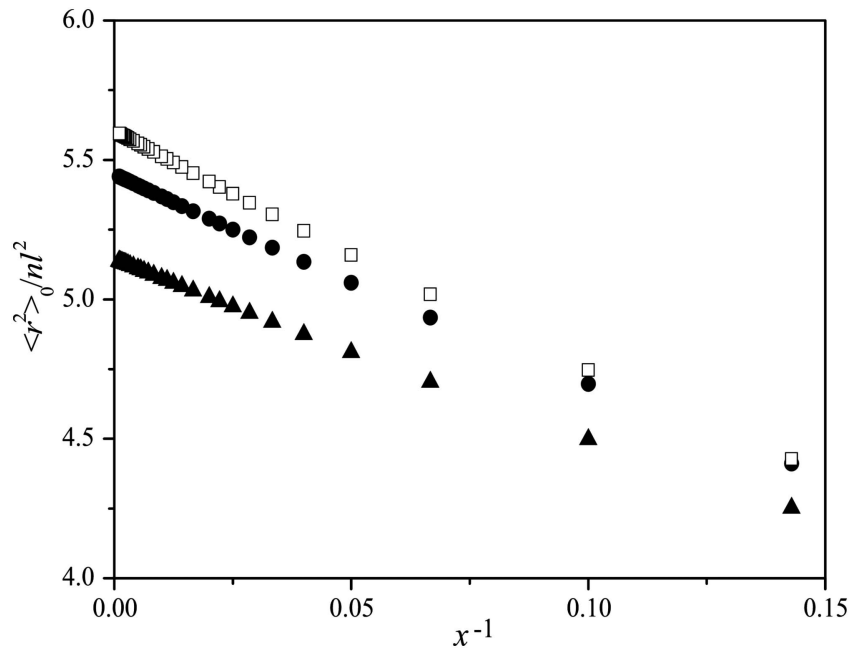

Figure 5 Characteristic ratios of poly((R)-3-hydroxybutyrate) (PHB) as a function of the reciprocal of degree of polymerization, calculated according to the refined rotational isomeric state (RIS) scheme with the free energies (Table 3) for the gas phase (filled circle) and ethylene dichloride (EDC) (filled triangle) and trifluoroethanol (TFE) (open square) solutions.

to-end distance, and $n l^{2}$ is the sum of square bond lengths. The interception at $x^{-1}=0$ yielded the characteristic ratio of the infinitelength chain as follows: $\left\langle r^{2}\right\rangle_{0} / n l^{2}=5.44$ (gas), 5.14 (EDC) and 5.60 (TFE). Marchessault et al. ${ }^{24,25}$ deduced from light scattering and optical rotatory dispersion experiments on PHB dissolved in chloroform, EDC or TFE that the PHB chain might form helical segments in these solutions. On the other hand, from viscosity and light scattering measurements for the solutions, Fujita et al. ${ }^{26-28}$ concluded that the PHB chain adopts random-coil configurations and considerably expands owing to unusually large excluded-volume effects. The slope of the tangent to an $\left\langle r^{2}>_{0} / n l^{2}\right.$ vs $x^{-1}$ curve at $x^{-1}=0$

$$
\left(\frac{\mathrm{d}<r^{2}>{ }_{0} / n l^{2}}{\mathrm{~d} x^{-1}}\right)_{x^{-1}=0}
$$

is known to provide a clue as to whether the main chain includes quasi-cyclic paths or helical segments. ${ }^{29,30}$ If the slope (equation (6)) at $x^{-1}=0$ is positive, such cyclic structures would probably be formed. ${ }^{31}$ In actual fact, all the plots in Figure 5 yield negative slopes at $x^{-1}=0$, thus suggesting that the PHB chain in the $\Theta$ state can be represented as a random coil.

Conformational analysis of PHB, based on the traditional RIS scheme including up to adjacent-bond correlations, yielded unperturbed chain dimensions (2.8 and 3.04) much smaller than the experimental observations. ${ }^{6}$ Phantom chain dynamics simulations was also performed for isolated 10, 60, 100 and 200 mer PHB chains at $25^{\circ} \mathrm{C}$, and the chain dimension derived therefrom was found to be sensitive to the degree of polymerization and the cutoff distance employed. ${ }^{6}$ As a consequence, the 100 mer chain with a $5.0-\AA$ cutoff yielded a characteristic ratio close to the experimental value. These examples indicate that inclusion of up to comparatively long-range bond correlations, at least, between the chiral centers is required for such model calculations to represent the $\Theta$ state.

In Table 5, the RIS calculations are summarized. The characteristic ratio, configurational entropy $\left(S_{\text {conf }}\right)$ and configurational internal energy $\left(U_{\text {conf }}\right)$ were calculated from the $\Delta G_{k}$ values at $25^{\circ} \mathrm{C}$ (Table 3) with the temperature set at 25 or $203^{\circ} \mathrm{C}$ (equilibrium melting point, 
Table 5 Configurational properties, thermodynamic quantities and average geometrical parameters of PHB, evaluated from refined RIS calculations $^{\mathrm{a}}$

\begin{tabular}{|c|c|c|c|c|c|c|c|}
\hline & \multirow[b]{2}{*}{ Bond } & \multicolumn{3}{|c|}{$25^{\circ} \mathrm{C}$} & \multicolumn{3}{|c|}{$203^{\circ} C^{b}$} \\
\hline & & Gas & $E D C$ & TFE & Gas & $E D C$ & TFE \\
\hline \multicolumn{8}{|l|}{ RIS Calculation } \\
\hline$<r^{2}>0 / n R$ for $x \rightarrow \infty$ & & 5.44 & 5.14 & 5.60 & & & \\
\hline$S_{\text {conf }}\left(\right.$ cal K$\left.^{-1} \mathrm{~mol}^{-1}\right)$ & & 3.29 & 2.73 & 2.64 & 4.15 & 3.88 & 3.84 \\
\hline$U_{\text {conf }}\left(\mathrm{kcal} \mathrm{mol}^{-1}\right)$ & & 0.58 & 0.49 & 0.49 & 0.90 & 0.92 & 0.94 \\
\hline \multicolumn{8}{|l|}{ Experimentc } \\
\hline$\Delta S_{\mathrm{u}}\left(\mathrm{cal} \mathrm{K}^{-1} \mathrm{~mol}^{-1}\right)$ & & & & & 6.67 & & \\
\hline$\Delta H_{\mathrm{u}}\left(\mathrm{kcal} \mathrm{mol}^{-1}\right)$ & & & & & 3.18 & & \\
\hline \multicolumn{8}{|l|}{ RIS Calculation } \\
\hline \multirow[t]{4}{*}{ Bond length ${ }^{\mathrm{d}}(\AA)$} & a & 1.356 & & & & & \\
\hline & $b$ & 1.455 & & & & & \\
\hline & c & 1.530 & & & & & \\
\hline & d & 1.520 & & & & & \\
\hline \multirow[t]{4}{*}{ Bond angle ${ }^{d}\left({ }^{\circ}\right)$} & a & 106.0 & & & & & \\
\hline & $b$ & 113.4 & & & & & \\
\hline & c & 110.9 & & & & & \\
\hline & d & 117.2 & & & & & \\
\hline \multirow[t]{5}{*}{ Dihedral angle $e^{d}\left({ }^{\circ}\right)$} & & t & $\mathrm{g}^{+}(\mathrm{c})^{\mathrm{e}}$ & $g^{-}$ & & & \\
\hline & a & -0.9 & 176.1 & & & & \\
\hline & $b$ & -27.4 & 115.0 & -99.2 & & & \\
\hline & c & 3.3 & 119.0 & -127.6 & & & \\
\hline & $d$ & -18.4 & 124.6 & -121.4 & & & \\
\hline
\end{tabular}

Abbreviations: EDC, ethylene dichloride; RIS, rotational isomeric state; TFE, trifluoroethanol. aUsing statistical weight matrices shown in Appendix (Supplementary Information), the $\Delta G_{k}$ values (Table 3) for the individual media (gas phase, EDC and TFE) at $25^{\circ} \mathrm{C}$ and geometrical parameters listed in Supplementary Table S2 (Supplementary Information).

The equilibrium melting point of PHB.

${ }^{c}$ Experimental values of entropy $\left(\Delta S_{u}\right)$ and enthalpy $\left(\Delta H_{u}\right)$ of fusion (reference 1)

dUsing the $\Delta G_{k}$ values for the TFE solution at $25^{\circ} \mathrm{C}$.

eThe symbol c represents the cis conformation for bond a.

$\left.T_{\mathrm{m}}^{0}\right) .{ }^{1}$ The experimental entropy $\left(\Delta S_{\mathrm{u}}\right)$ and enthalpy $\left(\Delta H_{\mathrm{u}}\right)$ of fusion of $\mathrm{PHB}^{1}$ are also shown in Table 5 . The $S_{\text {conf }} / \Delta S_{\mathrm{u}}$ ratio (about $60 \%$ ) is comparable to that $(65 \%)$ of PET but smaller than those $(80-90 \%)$ of polyethers and polysulfides. ${ }^{32}$ As compared with PET that gives a negative $U_{\text {conf }}{ }^{7}$ PHB may readily crystallize because of its

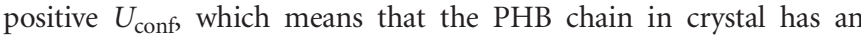
internal energy lower than in melt by $-U_{\text {conf }}{ }^{32}$ Inasmuch as the bond conformations of PHB were calculated from $\Delta G_{k}$ 's of dimer under the conformational restriction (Supplementary Table S1), bonds $\mathrm{a}, \mathrm{b}, \mathrm{c}$ and $\mathrm{d}$, respectively, have larger fractions in the $\mathrm{t}, \mathrm{t}$, $\mathrm{g}^{+}$and $\mathrm{g}^{+}$states than bonds $2-5$ of monomer (Table 4 ). The geometrical parameters averaged at $25^{\circ} \mathrm{C}$ are also listed in Table 5 .

\section{Solution properties of $\mathrm{PHB}$}

Solution properties of PHB have been reported by, for example, Marchessault et al., ${ }^{24,25}$ Fujita et al. ${ }^{26-28}$ and Huglin et al. ${ }^{33}$ Of them, Fujita's data are discussed herein for comparison with our RIS calculations, because biosynthetic PHB was carefully fractionated into a number of samples and each of them underwent both viscosity and light-scattering measurements. In their studies, the $\Theta$ condition (solvent and temperature) of PHB itself could not be found. Instead, the unperturbed dimension of PHB was estimated indirectly from Stockmayer-Fixman plots to be $\left\langle S^{2}>_{0} / M_{\mathrm{w}}=1.27\right.$ $\times 10^{-17} \mathrm{~cm}^{2},{ }^{27}$ where $\left\langle S^{2}>_{0}\right.$ is unperturbed mean-square radius of gyration, and $M_{\mathrm{w}}$ is weight-average molecular weight. Later on, they found the $\Theta$ condition (butyl chloride and $13^{\circ} \mathrm{C}$ ) of poly $(\mathrm{D}, \mathrm{L}-\beta$ - methyl $\beta$-propiolactone) (PMPL) and determined its unperturbed dimension as $<S^{2}>_{0} / M_{\mathrm{w}}=1.05 \times 10^{-17} \mathrm{~cm}^{2}$. On the basis of the experimental fact that PMPL is identical with PHB in all solutions properties, they concluded that the unperturbed dimension of PMPL must also be applicable to PHB and replaced the former $\left\langle S^{2}\right\rangle_{0} / M_{\mathrm{w}}$ with the latter. ${ }^{28}$ The correct $\left\langle S^{2}\right\rangle_{0} / M_{\mathrm{w}}$ value can be converted to a $\left\langle r^{2}>_{0} / n R^{2}\right.$ value of 6.30 with the bond lengths shown in Table 5 .

According to the two-parameter theory of polymer solutions, ${ }^{34-36}$ the dimension $\left(<S^{2}>^{1 / 2}\right.$ or $\left.<r^{2}>^{1 / 2}\right)$ of a real polymer chain may be expressed by the unperturbed dimension and expansion factor. The latter parameter is defined as

$$
\alpha_{S}^{2}=\frac{<S^{2}>}{<S^{2}>_{0}}
$$

or

$$
\alpha_{r}^{2}=\frac{<r^{2}>}{<r^{2}>_{0}}
$$

The expansion factors can be calculated by, for example, the DombBarrett equations ${ }^{37}$

$$
\alpha_{S}^{2} / \alpha_{r}^{2}=0.933+0.067 \exp \left[-\left(0.85 z+1.39 z^{2}\right)\right]
$$

and

$$
\alpha_{r}^{2}=\left[1+10 z+\left(\frac{70}{9} \pi+\frac{10}{3}\right) z^{2}+8 \pi^{3 / 2} z^{3}\right]^{2 / 15}
$$

The excluded-volume parameter $z$ is given by

$$
z=\left(\frac{3}{2 \pi}\right)^{3 / 2}\left(\frac{B}{A^{3}}\right) M^{1 / 2}
$$

where

$$
A^{2}=\frac{<r^{2}>_{0}}{M}=\frac{6<S^{2}>_{0}}{M}
$$

and

$$
B=\frac{\beta}{M_{0}^{2}}
$$

with $M$ being the molecular weight, $\beta$ the binary cluster integral for segment-segment interactions, and $M_{0}$ the formula mass of the repeating unit.

From inherent viscosities of PMPL in the $\Theta$ and good solvents, Hirosye et al..$^{28}$ determined the $\left\langle S^{2}>_{0} / M_{\mathrm{w}}\right.$ and $\beta$ values for the TFE solutions at $25^{\circ} \mathrm{C}$ of PMPL and PHB to be $1.05 \times 10^{-17} \mathrm{~cm}^{2}$ and $159 \times 10^{-24} \mathrm{~cm}^{3}$, respectively. Miyaki et al. ${ }^{27}$ reported static light scattering (SLS) data such as $M_{\mathrm{w}}$ and $\left\langle S^{2}\right\rangle$ of PHB and PMPL dissolved in TFE at $25^{\circ} \mathrm{C}$. For the detailed SLS data, see Supplementary Table S3 (Supplementary Information). Accordingly, we have examined the consistency between the viscosity and SLS data as follows.

To distinguish between the viscosity and SLS data, we will hereafter suffix the former and latter with $(\eta)$ and $(\lambda)$, respectively. The expansion factor $\alpha_{S}^{2}$ was calculated with equation (9) and (10) from $\beta(\eta) \quad\left(159 \times 10^{-24} \mathrm{~cm}^{3}\right)$ and $\left[<S^{2}>_{0} / M_{\mathrm{w}}\right](\eta) \quad(1.05 \times$ $\left.10^{-17} \mathrm{~cm}^{2}\right)$ and used to evaluate $\left\langle r^{2}>_{0}(\lambda)\right.$ according to $<r^{2}>_{0}(\lambda)=6<S^{2}>_{0}(\lambda)=6<S^{2}>(\lambda) / \alpha_{S}^{2}$. The degree of polymerization $x(\lambda)$ was estimated from $M_{\mathrm{w}}(\lambda) / M_{0}$ and used to calculate $n l^{2}(\lambda)$ with $n l^{2}(\lambda)=\left(n l^{2}\right.$ of the repeating unit $) \times x(\lambda)$. Finally, the characteristic ratio, $\left[<r^{2}>_{0} / n l^{2}\right](\lambda)$, was evaluated from $\left\langle r^{2}>_{0}(\lambda)\right.$ and $n l^{2}(\lambda)$. The SLS data on 14 fractions of PHB $\left(M_{\mathrm{w}}(\lambda)=51.0-910 \times 10^{4}\right)^{27}$ and 4 fractions of PMPL $\left(M_{\mathrm{w}}(\lambda)=\right.$ $\left.8.65-15.0 \times 10^{4}\right)^{27,28}$ were analyzed, and all the results are listed 


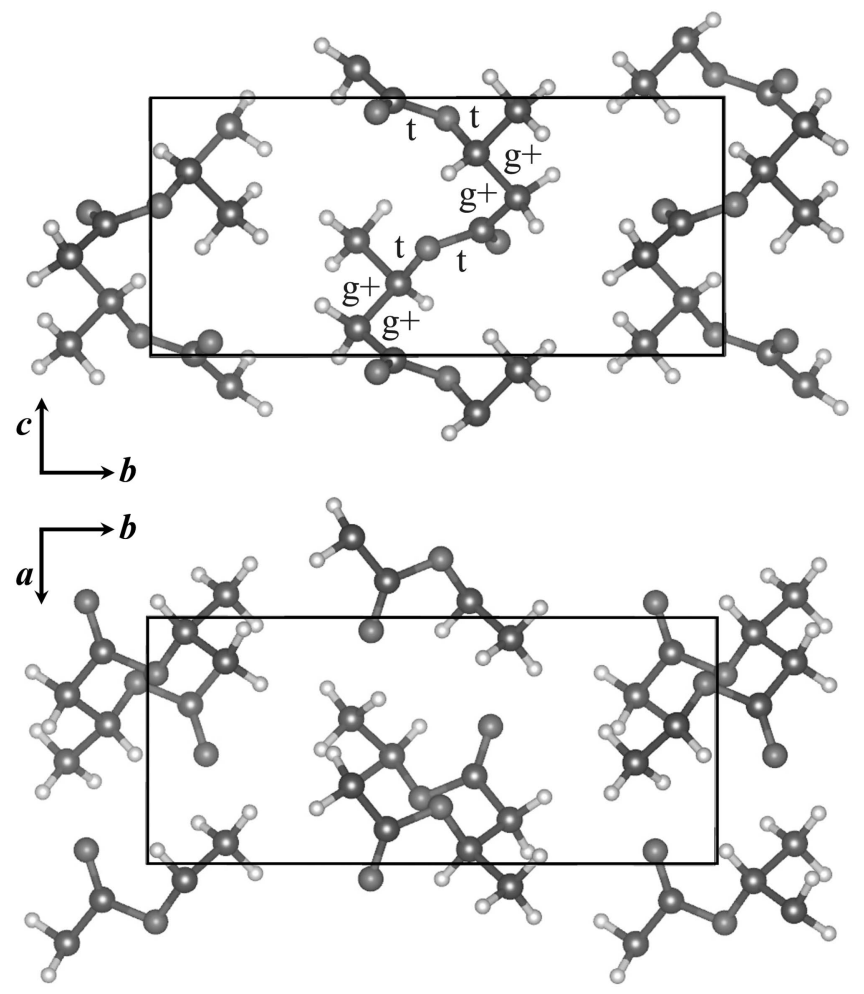

Figure 6 Crystal structure of poly((R)-3-hydroxybutyrate) (PHB), ${ }^{39}$ depicted by the VESTA software. ${ }^{41}$. A full color version of this figure is available at Polymer Journal online.

in Supplementary Table S3 (Supplementary Information). The $\left[\left\langle r^{2}\right\rangle_{0} / n l^{2}\right](\lambda)$ values thus evaluated fall into narrow ranges: $6.19 \pm 0.28$ (PHB); $6.12 \pm 0.31$ (PMPL). These results are in good agreement with the characteristic ratio $(6.30)$ derived from $\left[\left\langle S^{2}\right\rangle_{0} /\right.$ $\left.M_{\mathrm{w}}\right](\eta)$ of $1.05 \times 10^{-17} \mathrm{~cm}^{2}$, that is, the viscosity and SLS data are fully consistent with each other. On this basis, we have accepted $\left\langle r^{2}>_{0} / n l^{2}=6.1-6.3\right.$ as the unperturbed chain dimension of $\mathrm{PHB}$ at $25^{\circ} \mathrm{C}$. This experimental value is comparable to our RIS calculations on the TFE solution at $25^{\circ} \mathrm{C}\left(<r^{2}>_{0} / n l^{2}=5.60\right)$.

\section{Crystal structure of PHB}

The crystal structure of PHB has been determined by, for example, Cornibert and Marchessault, ${ }^{38}$ Yokouchi et al. ${ }^{39}$ and Brüchner et al. ${ }^{40}$ According to Yokouchi et al., the $\mathrm{PHB}$ chains are packed in an orthorhombic cell of $P 2{ }_{1} 2{ }_{1} 2_{1}-D_{2}^{4}$ with $a=5.76 \AA, b=13.20 \AA$, and $c$ (fiber axis) $=5.96 \AA$, and two molecular chains are pass through the unit cell as shown in Figure 6. The PHB chain forms a left-handed $2_{1}$ helix of the most stable $\operatorname{ttg}^{+} \mathrm{g}^{+}$conformation (Table 3). The dihedral angles of bonds a- $\mathrm{d}$ in the crystal are, respectively, $5^{\circ}\left(3.0^{\circ}\right),-28^{\circ}$ $\left(-28.5^{\circ}\right), 128^{\circ}\left(119.3^{\circ}\right)$ and $133^{\circ}\left(134.4^{\circ}\right)$, being in good agreement with those (in the parentheses) predicted by our MO calculations for the $\operatorname{tgg}^{+} \mathrm{g}^{+}$conformation of dimer. This fact suggests that the PHB chain in the crystal may be nearly as unconstrained as in the isolated state; no specific intermolecular interactions seem to disturb its inherent conformational stability.

By crystal orbital calculations, $\mathrm{Li}$ and $\mathrm{Wu}^{42}$ have investigated the stability of the $2_{1}\left(\operatorname{ttg}^{+} \mathrm{g}^{+}\right), 3_{1}\left(\mathrm{ttg}^{+} \mathrm{t}\right), 4_{1}\left(\mathrm{tg}^{-} \mathrm{tt}\right)$ helical structures of PHB; the three helices adopt the conformations given in the parentheses. From the theoretical computations, they derived the following conclusions: The $3_{1}$ helix is energetically more favorable
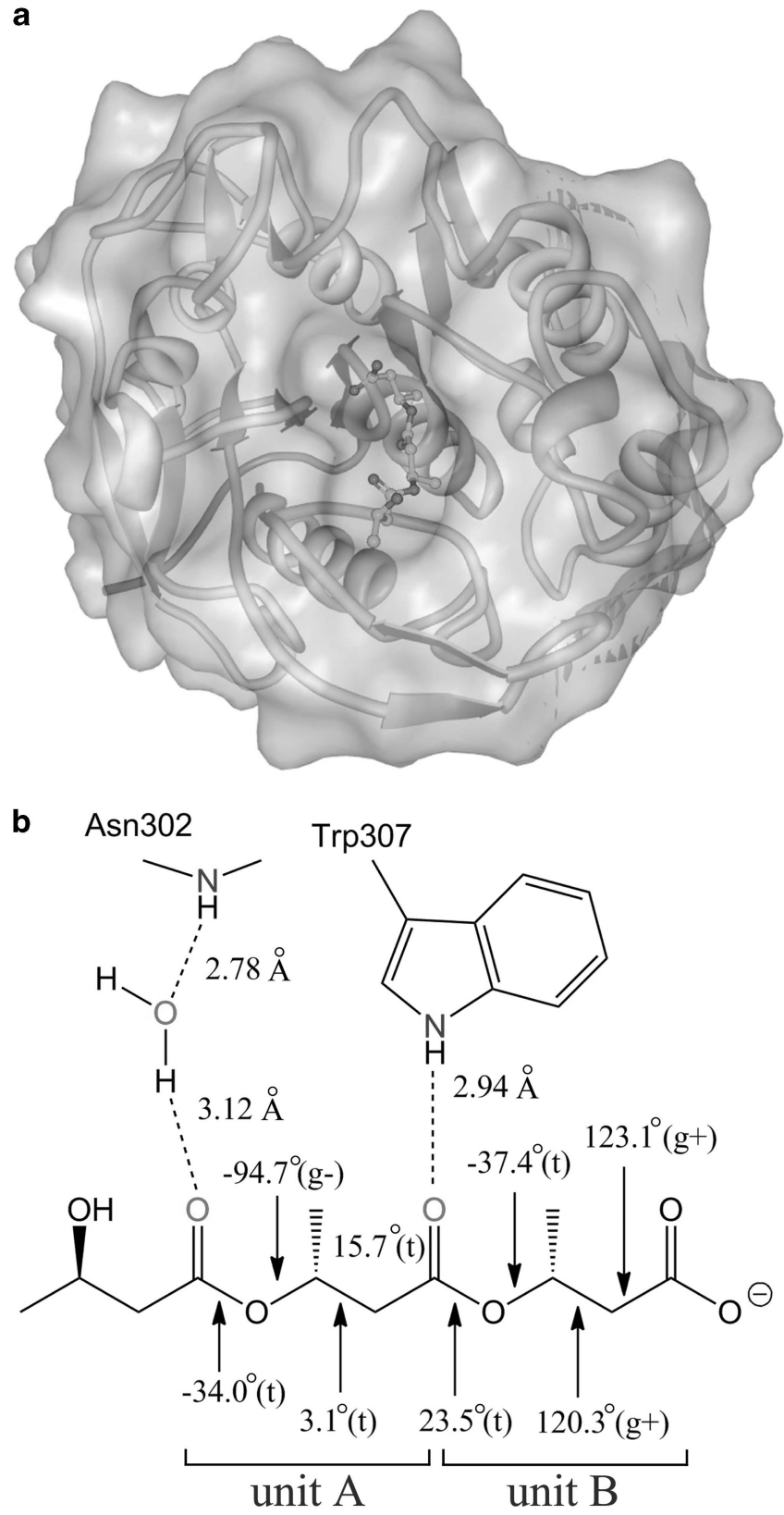

Figure 7 Crystal structure of a poly((R)-3-hydroxybutyrate) (PHB) depolymerase extracted from Penicillium funiculosum and complexed with a trimeric ( $R$ )-3-hydroxybutyrate (HB) substrate (located at the center): ${ }^{43}$ (a) The structural data stored in the Protein Data Bank (PDB ID: 2D81) were visualized by the Protein Workshop software; ${ }^{44}$ (b) The schematic diagram shows dihedral angles (conformations) of the skeletal bonds and $\mathrm{N} \ldots \mathrm{O}$ and $\mathrm{O} \ldots \mathrm{O}$ distances of the hydrogen bonds. A full color version of this figure is available at Polymer Journal online.

than $2_{1}$, whereas the $2_{1}$ helix $\left(1.347 \mathrm{~g} \mathrm{~cm}^{-3}\right)$ is denser than $3_{1}$ $\left(0.912 \mathrm{~g} \mathrm{~cm}^{-3}\right)$. As a consequence, the crystalline PHB chain prefers the $2_{1}$ helix to $3_{1}$. It should be noted that the crystal density was experimentally determined to be $1.26 \mathrm{~g} \mathrm{~cm}^{-3}$. ${ }^{39}$ The dihedral angles of bonds a- $\mathrm{d}$ were reported by them to be $3.1^{\circ},-23.9^{\circ}, 120.9^{\circ}$ and $143.6^{\circ}$, deviating somewhat from the X-ray crystallographic data. Our MO calculations also indicate that the three conformations are comparatively stable; in monomer, the $\operatorname{ttg}^{+} \mathrm{t}$, state $\left(3_{1}\right.$ helix) is the lowest in $\Delta G_{k}$, whereas, in dimer, the $\operatorname{ttg}^{+} \mathrm{g}^{+}$conformation $\left(2_{1}\right)$ is 
more stable than $\operatorname{ttg}^{+} \mathrm{t}\left(3_{1}\right)$. Accordingly, our results do not support all of their conclusions.

Most aliphatic polyesters melt at temperatures lower than $T_{\mathrm{m}}^{0}$ of $\mathrm{PHB}$, as mentioned in the Introduction; hence, $\mathrm{PHB}$ is rather exceptional. Its high equilibrium melting point, given by $T_{\mathrm{m}}^{0}=\Delta H_{\mathrm{u}} / \Delta S_{\mathrm{u}}$, is attributed to the small $\Delta S_{\mathrm{u}}$, that is, the small $S_{\text {conf, }}$ which stems from a limited number of possible conformations. (see for example, $\Delta S_{\mathrm{u}}=11.6 \mathrm{cal} \mathrm{K}^{-1} \mathrm{~mol}^{-1}$ and $\Delta H_{\mathrm{u}}=$ $6.41 \mathrm{kcal} \mathrm{mol}^{-1}$ of PET at $T_{\mathrm{m}}^{0}=280^{\circ} \mathrm{C}$; PET has four rotatable bonds in the repeating unit and forms stable interchain $\pi / \pi$ stacking. $)^{7}$ As will be discussed below, the high melting point of $\mathrm{PHB}$ may not be a requisite for the bacteria but an outgrowth of the optically-active crowded structure necessary for the molecular recognition by the enzymes.

\section{Interaction between $\mathrm{PHB}$ and $\mathrm{PHB}$ depolymerase}

A PHB depolymerase extracted from Penicillium funiculosum, complexed with a trimeric $(R)$-3-hydroxybutyrate $(\mathrm{HB})$ substrate and crystallized, was subjected to synchrotron X-ray diffraction, and the crystal structure was determined. ${ }^{43}$ Formed on the surface of the depolymerase is a crevice, where the HB substrate is bound as shown in Figure $7 \mathrm{a}$ and $\mathrm{b}$. Figure $7 \mathrm{~b}$ schematically illustrates the conformation and hydrogen bonds of the $\mathrm{HB}$ substrate, which contains two sets of bonds a-d (designated here as units A and B). The dihedral angles (conformations) of bonds $\mathrm{a}, \mathrm{b}, \mathrm{c}$ and $\mathrm{d}$ are, respectively, as follows: unit $\mathrm{A},-34.0^{\circ}(\sim \mathrm{t}),-94.7^{\circ}\left(\mathrm{g}^{-}\right), 3.1^{\circ}(\mathrm{t})$, and $15.7^{\circ}(\mathrm{t})$; unit $\mathrm{B}$, $23.5^{\circ}(\mathrm{t}),-37.4^{\circ}(\sim \mathrm{t}), 120.3^{\circ}\left(\mathrm{g}^{+}\right)$and $123.1^{\circ}\left(\mathrm{g}^{+}\right)$. Unit $\mathrm{B}$ lies in the most stable conformation $\left(\mathrm{ttg}^{+} \mathrm{g}^{+}, k=5\right.$ in Table 3 ), although the dihedral angles somewhat deviate from our MO calculations (see the previous section). Unit A is trapped in a metastable conformation ( $\operatorname{tg}^{-} \mathrm{tt}, k=19$ in Table 3 ) but greatly stabilized by an $\mathrm{N}-\mathrm{H} \cdots \mathrm{O}=\mathrm{C}$ hydrogen bond with Trp307 and an $\mathrm{O}-\mathrm{H} \cdots \mathrm{O}=\mathrm{C}$ one with water. It is known that $\mathrm{N}-\mathrm{H} \cdots \mathrm{O}=\mathrm{C}$ hydrogen bonds of polypeptides cause stabilization of -4 to $-6 \mathrm{kcal} \mathrm{mol}^{-1} \cdot{ }^{45}$ Enthalpies of $\mathrm{O}-\mathrm{H} \cdots \mathrm{O}=\mathrm{C}$ hydrogen bonds of formic acid and acetic acid were experimentally estimated to be $-7 \mathrm{kcal} \mathrm{mol}^{-1}$. 46

It is not fortuitous for the $\mathrm{HB}$ substrate to fit the crevice. Only the $(R)$-HB isomer can readily adopt the two stable conformations. The methyl group at the $(R)$-asymmetry carbon, being indispensable for the HB units to direct its characteristic groups (for example, the $\mathrm{C}=\mathrm{O}$ bond) toward the hydrogen-bond partners (for example, the $\mathrm{H}-\mathrm{N}$ group of Trp307), does not sterically hinder the HB substrate from fitting into the active site of the enzyme. Bachmann and Seebach $^{47}$ have investigated the degradation of $\mathrm{HB}$ oligomers including various stereosequences of $(R)$ and $(S)$ repeating units by a PHB depolymerase extracted from Alcaligenes faecalis and found that the cleavage of the HB substrate occurs only between the $(R)$ units; at least two successive $(R)$ units are requisite for the biodegradation.

\section{CONCLUSIONS}

$A b$ initio statistical mechanics based on the RIS scheme and MO calculations has been applied to PHB to elucidate its conformational characteristics and configurational properties. This article has presented fully consistent interpretations on its bond conformations, solution properties, crystal structure, thermal properties and interactions with the $\mathrm{PHB}$ depolymerase in terms of the conformational characteristics and, furthermore, reasonable suggestions as to why $\mathrm{PHB}$ is suitable for a biodegradable reserve substance. In conclusion, $\mathrm{PHB}$ is a special polymer resulting from molecular design of nature; its unique properties and functions were created from the combination of the simple atomic groups, viz., one methine, one methylene, one methyl and one ester groups.

\section{CONFLICT OF INTEREST}

The authors declare no conflict of interest.

\section{ACKNOWLEDGEMENTS}

This study was partly supported by a Grant-in-Aid for Scientific Research (C) (22550190) from the Japan Society for the Promotion of Science.

1 Mandelkern, L. Crystallization of Polymer Volume 1 Equilibrium Concept Ch. 6 (Cambridge University Press, New York, 2002).

2 Wunderlich, B. Macromolecular Physics Volume 3 Crystal Melting Ch. 8 (Academic Press, Cambridge, UK, 1980).

3 Biopolymers: Volume $3 b$ Polyesters // Properties and Chemical Synthesis Doi, Y. \& Steinbüchel, A. (eds). (Wiley-VCH, Weinheim, Germany, 2002).

4 Flory, P. J. Statistical Mechanics of Chain Molecules (Wiley \& Sons, New York, 1969).

5 Mattice, W. L. \& Suter, U. W. Conformational Theory of Large Molecules: The Rotational Isomeric State Model in Macromolecular Systems (Wiley \& Sons, New York, 1994).

6 Kyles, R. E. \& Tonelli, A. E. Conformational characteristics of poly(D- $\beta$-hydroxybutyrate). Macromolecules 36, 1125-1131 (2003).

7 Sasanuma, Y. Conformational characteristics, configurational properties, and thermodynamic characteristics of poly(ethylene terephthalate) and poly(ethylene-2, 6-naphthalate). Macromolecules 42, 2854-2862 (2009).

8 Sasanuma, Y. \& Suzuki, N. Influence of weak attractive interactions on structures and properties of poly(trimethylene terephthalate). Macromolecules 42, 7203-7212 (2009)

9 Sasanuma, Y., Asai, S. \& Kumagai, R. Conformational characteristics and configurational properties of poly(ethylene oxide-alt-ethylene sulfide). Macromolecules 40 , 3488-3497 (2007)

10 Doi, Y., Kunioka, M., Nakamura, Y. \& Soga, K. Proton and carbon-13 NMR analysis of poly( $\beta$-hydroxybutyrate) isolated from Bacillus megaterium. Macromolecules 19, 1274-1276 (1986)

11 Doi, Y., Kunioka, M., Nakamura, Y. \& Soga, K. Nuclear magnetic resonance studies on poly( $\beta$-hydroxybutyrate) and a copolyester of $\beta$-hydroxybutyrate and $\beta$-hydroxyvalerate isolated from Alcaligenes eutrophus H16. Macromolecules 19, 2860-2864 (1986).

12 Kamiya, N., Inoue, Y., Yamamoto, Y., Chûjô, R. \& Doi, Y. Conformational analysis of poly(3-hydroxybutyrate- co-3-hydroxyvalerate) in solution by proton NMR spectroscopy. Macromolecules 23, 1313-1317 (1990).

$13 \mathrm{Li}$, J., Uzawa, J. \& Doi, Y. Conformational behavior of methyl (3 R)-3-[( $3^{\prime}$ R)-3' hydroxybutanoyl]oxybutanoate in solutions: effect of intramolecular hydrogen bond Bull. Chem. Soc. Jpn 70, 1887-1893 (1997).

$14 \mathrm{Li}$, J., Uzawa, J. \& Doi, Y. Conformational analysis of oligomers of (R)-3-hydroxybutanoic acid in solutions by ${ }^{1} \mathrm{H}$ NMR spectroscopy. Bull. Chem. Soc. Jpn 71, 16831689 (1998).

15 Waser, P., Rueping, M., Seebach, D., Duchardt, E. \& Schwalbe, H. On the solution structure of PHB: preparation and NMR analysis of isotopically labeled oligo[(R)-3hydroxybutanoic acids] (OHBs). Helv. Chem. Acta 84, 1821-1845 (2001).

16 Budzelaar, P. H. M. gNMR, version 5.0 (IvorySoft \& Adept Scientific plc, Letchworth, UK, 2004).

17 Frisch, M. J., Trucks, G. W., Schlegel, H. B., Scuseria, G. E., Robb, M. A., Cheeseman, J. R., Montgomery, Jr. J. A., Vreven, T., Kudin, K. N., Burant, J. C., Millam, J. M., lyengar, S. S., Tomasi, J., Barone, V., Mennucci, B., Cossi, M., Scalmani, G., Rega, N., Petersson, G. A., Nakatsuji, H., Hada, M., Ehara, M., Toyota, K., Fukuda, R., Hasegawa, J., Ishida, M., Nakajima, T., Honda, Y., Kitao, O., Nakai, H., Klene, M. Li, X., Knox, J. E., Hratchian, H. P., Cross, J. B., Bakken, V., Adamo, C., Jaramillo, J. Gomperts, R. Stratmann, R. E., Yazyev, O., Austin, A. J., Cammi, R., Pomelli, C. Ochterski, J. W., Ayala, P. Y., Morokuma, K., Voth, G. A., Salvador, P., Dannenberg, J. J., Zakrzewski, V. G., Dapprich, S., Daniels, A. D., Strain, M. C., Farkas, O., Malick, D. K., Rabuck, A. D., Raghavachari, K., Foresman, J. B., Ortiz, J. V., Cui, Q., Baboul, A. G., Clifford, S., Cioslowski, J., Stefanov, B. B., Liu, G., Liashenko, A., Piskorz, P., Komaromi, I., Martin, R. L., Fox, D. J., Keith, T., Al-Laham, M. A., Peng, C. Y., Nanayakkara, A., Challacombe, M., Gill, P. M. W., Johnson, B., Chen, W., Wong, M. W., Gonzalez, C. \& Pople, J. A. Gaussian03 Revision D.01 (Gaussian Inc., Wallingford, CT, 2004)

18 Cancès, E., Mennucci, B. \& Tomasi, J. A new integral equation formalism for the polarizable continuum model: theoretical background and applications to isotropic and anisotropic dielectrics. J. Chem. Phys 107, 3032-3041 (1997).

19 Helgaker, T., Watson, M. \& Handy, N. C. Analytical calculation of nuclear magnetic resonance indirect spin-spin coupling constants at the generalized gradient approximation and hybrid levels of density-functional theory. J. Chem. Phys 113, 9402-9409 (2000)

20 Anteunis, J. O., Tavernier, D. \& Borremans, F. A review on the conformational aspects in the 1,3-dioxane system. Heterocycles 4, 293-371 (1976).

21 Sasanuma, Y. Conformational analysis of poly(propylene oxide) and its model compound 1,2-dimethoxypropane. Macromolecules 28, 8629-8638 (1995). 
22 Sasanuma, Y. Solvent effect on the conformation of 1,2-dimethoxypropane. J. Phys. Chem. 51, 13486-13488 (1994).

23 Bondi, A. van der Waals volumes and radii. J. Phys. Chem. 68, 441-451 (1964).

24 Marchessault, R. H., Okamura, K. \& Su, C. J. Physical properties of poly( $\beta$-hydroxy butyrate). II. Conformational aspects in solution. Macromolecules 3, 735-740 (1970).

25 Cornibert, J., Marchessault, R. H., Benoit, H. \& Weill, G. Physical properties of poly $(\beta$ hydroxy butyrate). III. Folding of helical segments in 2,2,2-trifluoroethanol. Macromolecules 3, 741-746 (1970).

26 Akita, S., Einaga, Y., Miyaki, Y. \& Fujita, H. Solution properties of poly(D- $\beta$ hydroxybutyrate). 1. Biosynthesis and characterization. Macromolecules 9, 774-780 (1976).

27 Miyaki, Y., Einaga, Y., Hirosye, T. \& Fujita, H. Solution properties of poly(D- $\beta$ hydroxybutyrate). 2. Light scattering and viscosity in trifluoroethanol and behavior of highly expanded polymer coils. Macromolecules 10, 1356-1364 (1977).

28 Hirosye, T., Einaga, Y. \& Fujita, H. Excluded-volume effects in dilute polymer solutions. VIII. Poly(D,L- $\beta$-methyl $\beta$-propiolactone) in several solvents and reanalysis of data on poly(D- $\beta$-hydroxybutyrate). Polym. J. 11, 819-826 (1979).

29 Vacatello, M. \& Flory, P. J. Conformational statistics of poly(methyl methacrylate). Macromolecules 19, 405-415 (1986).

30 Mattice, W. L., Helfer, C. A. \& Sokolov, A. P. Persistence length and finite chain length effect on characteristic ratios. Macromolecules 37, 4711-4717 (2004).

31 Sasanuma, Y. \& Kumagai, R. Conformational characteristics and configurational properties of poly(ethylene imine- alt-ethylene sulfide) and the role of the secondary amine group as a junction of attractive interactions. Macromolecules 40, 7393-7399 (2007).

32 Sasanuma, Y., Watanabe, A. \& Tamura, K. Structure-property relationships of polyselenoethers $\left[-\left(\mathrm{CH}_{2}\right)_{y} \mathrm{Se}-\right]_{x}(y=1,2$, and 3$)$ and related polyethers and polysulfides. J. Phys. Chem. B 112, 9613-9624 (2008).

33 Huglin, M. B. \& Radwan, M. A. Unperturbed dimensions of poly( $\beta$-hydroxybutyrate) in single and binary solvents. Polymer 32, 1293-1298 (1991).

34 Flory, P. J. Principles of Polymer Chemistry (Cornell University Press, Ithaca, NY 1953).
35 Yamakawa, H. Modern Theory of Polymer Solutions (Harper \& Row, New York, 1971). 36 Fujita, H. Polymer Solutions (Elsevier Science, New York, 1990).

37 Domb, C. \& Barrett, A. J. Universality approach to the expansion factor of a polymer chain. Polymer 17, 179-184 (1976).

38 Cornibert, J. \& Marchessault, R. H. Physical properties of poly- $\beta$-hydroxybutyrate: IV. Conformational analysis and crystalline structure. J. Mol. Biol. 71, 735-756 (1972).

39 Yokouchi, M., Chatani, Y., Tadokoro, H., Teranishi, K. \& Tani, H. Structural studies of polyesters: 5. Molecular and crystal structures of optically active and racemic poly( $\beta$-hydroxybutyrate). Polymer 14, 267-272 (1973).

40 Brüchner, S., Meille, S. V., Malpezzi, L., Cesàro, A., Navarini, L. \& Tombolini, R. The structure of poly(D-(-)-beta-hydroxybutyrate). A refinement based on the Rietveld method. Macromolecules 21, 967-972 (1988).

41 Momma, K. \& Izumi, F. VESTA 3 for three-dimensional visualization of crystal, volumetric and morphology data. J. Appl. Crystallogr. 44, 1272-1276 (2011).

$42 \mathrm{Li}, \mathrm{Y} . \& \mathrm{Wu}, \mathrm{Y} . \mathrm{A}$ theoretical study on the structure of poly((R)-3-hydroxybutanoic acid). J. Phys. Chem. A 107, 5128-5137 (2003).

43 Hisano, T., Kasuya, K., Tezuka, Y., Ishii, N., Kobayashi, T., Shiraki, M., Oroudjev, E., Hansma, H., Iwata, T., Doi, Y., Saito, T. \& Miki, K. The crystal structure of polyhydroxybutyrate depolymerase from Penicillium funiculosum provides insights into the recognition and degradation of biopolyesters. J. Mol. Biol. 356, 993-1004 (2006).

44 Moreland, J. L., Gramada, A., Buzko, O. V., Zhang, Q. \& Bourne, P. E. The molecular biology toolkit (MBT): a modular platform for developing molecular visualization applications. BMC Bioinformatics 6, 21 (2005).

45 Deshmukh, M. M. \& Gadre, S. R. Estimation of $\mathrm{N}-\mathrm{H} \cdots \mathrm{O}=\mathrm{C}$ intramolecular hydrogen bond energy in polypeptides. J. Phys. Chem. A 113, 7927-7932 (2009).

46 Jeffrey, G. A. An Introduction to Hydrogen Bonding Ch. 11 (Oxford University Press, New York, 1997).

47 Bachmann, B. M. \& Seebach, D. Investigation of the enzymatic cleavage of diastereomeric oligo(3-hydroxybutanoates) containing two to eight HB units. A model for the stereoselectivity of PHB depolymerase from Alcaligenes faecalis $T_{1}$. Macromolecules 32, 1777-1784 (1999).

Supplementary Information accompanies the paper on Polymer Journal website (http://www.nature.com/pj) 